\title{
ELIMINAÇÃO DE VÍRUS DO COMPLEXO SOROSE DOS CITROS POR MICROENXERTIA ASSOCIADA A TERMOTERAPIA*
}

\author{
SÉRGIO A. CARVALHO, FRANCISCA A. SANTOS \& MARCOS A. MACHADO
}

Centro de Citricultura Sylvio Moreira - IAC, Cx. Postal 04, CEP 13.490-970, Cordeirópolis, SP

(Aceito para publicação em 19/02/2002)

Autor para correspondência: Sérgio Alves Carvalho

CARVALHO, S.A., SANTOS, F.A. \& MACHADO, M.A. Eliminação de vírus do complexo sorose de citros por microenxertia associada a termoterapia. Fitopatologia Brasileira 27:306-308. 2002.

\begin{abstract}
RESUMO
A microenxertia de ápices caulinares tem sido utilizada com $100 \%$ de sucesso na eliminação do vírus da tristeza (Citrus tristeza virus) e dos viróides da exocorte (Citrus exocortis viroid - CEVd) e cachexia-xiloporose de materiais do Banco Ativo de Germoplasma de Citros do Centro de Citricultura Sylvio Moreira CCSM-IAC. Para o complexo da sorose, entretanto, esta técnica tem apresentado somente $60 \%$ de eficiência, indicando a necessidade de sua associação com termoterapia para garantir a eliminação viral. Para tanto, mudas originadas de borbulhas infetadas com sorose foram mantidas em câmara climática com 16 h de luz a $38^{\circ} \mathrm{C}$ e 8 h no escuro a $32{ }^{\circ} \mathrm{C}$ e utilizadas para a obtenção dos ápices

caulinares empregados na microenxertia. Após o pegamento, o conjunto micro porta-enxerto e brotação foi sobre-enxertado em limoeiro (Citrus limonia) 'Cravo' com sete meses de idade e mantido em condições de casa de vegetação. Clones de laranjeiras doces (Citrus sinsensis) 'Lima', 'Rubi', 'Piralima', 'Salustiana', 'João Nunes', 'Rosa' e 'Pêra Caire' tratados desta maneira, comprovaram eficiência de $100 \%$ de eliminação do complexo sorose, conforme indexação realizada empregando-se laranjeira 'Do Céu' como planta indicadora.

Palavras-chave adicionais: viroses, tratamento térmico, limpeza clonal.

\section{ABSTRACT \\ Psorosis virus complex elimination from citrus by shoot-tip grafting associated to thermotherapy}

Shoot-tip grafting has been $100 \%$ efficient in eliminating the Citrus tristeza virus (CTV), Citrus exocortis viroid (CEVd) and cachexia-xiloporosis viroid from varieties of the citrus germplasm bank at the Centro de Citricultura Sylvio Moreira CCSM-IAC. However, this technique has shown to be only $60 \%$ efficient in getting rido of the citrus psorosis virus complex, showing the necessity of association with thermotherapy to assure a complete virus-free condition. For this experiment, nursery trees were maintained in a climatic chamber at $38{ }^{\circ} \mathrm{C}$ in $16 \mathrm{~h}$ light and

$32{ }^{\circ} \mathrm{C} 8 \mathrm{~h}$ darkness for 60 days, and the meristematic apices were used to shoot-tip graft. After the shooting of the meristematic part, this shoot tip graft was over grafted on seven-month old 'Rangpur' lime (Citrus limonia) seedlings, and developed under greenhouse conditions. Clones of sweet oranges (Citrus sinensis) 'Lima', 'Rubi', 'Piralima', 'Salustiana', 'João Nunes', 'Rosa' and 'Pêra Caire' treated this way had $100 \%$ success in psorosis virus elimination as shown by a biological index using 'Do Céu' sweet orange as the indicator plant.
\end{abstract}

Doenças do complexo sorose (sorose A, sorose B e mancha anelar dos citros, causada pelo Citrus ringspot virus (CtRSV) apresentam ampla distribuição entre variedades e espécies de citros. De etiologia viral, a sorose apresenta um período de até doze anos de incubação antes de expressar sintomas, que são caracterizados principalmente por fendilhamento e escamação de tronco e galhos de laranjeiras doce [Citrus sinensis (L.) Osbeck], tangerineiras (Citrus reticulata Blanco) e pomeleiros (Citrus paradisi Macf) (Müller \& Costa, 1993). A partir do uso de clones nucelares, a sorose $\mathrm{A}$, única forma descrita em nossas condições, deixou de ser problemática para a citricultura, embora surtos eventuais possam ocorrer, principalmente associados ao uso de borbulhas originadas de clones velhos.

Dois componentes virais de morfologia diferenciada

\footnotetext{
* Apoio: FAPESP, Fundag e CNPq
}

e com capa protéica, unidades de capsídeo de aproximadamente $48 \mathrm{KDa}$, têm sido associados a diferentes isolados de CtRSV e de sorose (Derrick et al., 1988; Garcia et al. 1994). Mais recentemente, considerando a similaridade entre partículas virais encontradas em diferentes fontes de sorose que causa forte descamação, estas foram descritas em um novo gênero Ophiovirus, como Citrus psorosis virus (CPsV) (Milne et al., 1996). Entretanto, a etiologia da doença ainda não está bem determinada, não havendo em muitos casos correlação entre a detecção molecular ou sorológica do CPsV e a expressão da doença no campo e em plantas indicadoras (Martin et al., 2001). Por esta razão, e pelo fato de não terem sido ainda completamente caracterizados os isolados em nossas condições, será adotado neste trabalho o termo genérico complexo sorose.

O melhor método de controle do complexo sorose é a prevenção, através do emprego de borbulhas sadias na 
Eliminação de vírus do complexo sorose dos citros por microenxertia...

produção de mudas. A eliminação de patógenos sistêmicos pode ser realizada atualmente através da microenxertia de ápices caulinares, sem os inconvenientes da juvenilidade associada ao uso de clones nucelares. No Centro de Citricultura Sylvio Moreira do Instituto Agronômico de Campinas (CCSM-IAC) a microenxertia de ápices caulinares tem sido utilizada isoladamente com alta eficiência na eliminação do vírus da tristeza (Citrus tristeza virus, CTV) família Closteroviridae, gênero Closterovirus e dos viróides da exocorte (Citrus exocortis viroid, CEVd) e cachexia/ xiloporose. Entretanto, para os do complexo sorose, para o qual também é necessário a indexação no Programa de Registro de Plantas Matrizes do Estado de São Paulo, esta técnica tem apresentado cerca de $37 \%$ de falha (Carvalho et al., 1998).

A termoterapia é uma maneira efetiva e ecológica de erradicar patógenos de material propagativo. Apesar de não ser efetiva na eliminação de CEVd e do viroide da cachexia/ xiloporose, esta técnica apresenta importante uso na eliminação de sorose A, sorose B, gomose côncava, impietratura, cristacortis, infeção variegada, "huanglongbin" ("greening”), CTV, "taatterleaf" e "vein enation" (Roistacher, 1985).

O objetivo deste trabalho foi avaliar os efeitos da microenxertia, associada à termoterapia, na eliminação total dos vírus do complexo da sorose em variedades de citros do CCSM-IAC.

Os trabalhos foram desenvolvidos no Laboratório de Biotecnologia do CCSM-IAC, em Cordeirópolis, SP. Foram avaliadas as variedades de laranjeira 'Lima', 'Rubi', 'Piralima', 'Salustiana', 'João Nunes', 'Rosa' e 'Pêra Caire', todas positivas para sorose, conforme resultados de testes biológicos.

A presença de vírus do complexo sorose no material trabalhado foi detectada por testes biológicos empregando-se plantas de limoeiro 'Cravo' (Citrus limonia Osbeck) com seis meses de idade. Foram enxertadas duas borbulhas das variedades em estudo e logo acima uma borbulha da indicadora laranjeira doce 'Do Céu', com quatro repetições, empregando-se também controles positivos e negativos. As plantas foram mantidas em casa de vegetação com temperatura diurna de $28{ }^{\circ} \mathrm{C}$ e noturna de $16{ }^{\circ} \mathrm{C}$. As leituras de sintomas nas folhas jovens foram realizadas duas vezes por semana, observando-se a ocorrência de manchas tipo "folha de carvalho" ou estrias cloróticas nos limbos foliares. Quando nenhum sintoma era observado até o amadurecimento das folhas, as plantas eram podadas para forçar a emissão de novas brotações, realizando-se pelo menos três outras leituras ou quantas necessárias para o aparecimento dos sintomas no controle positivo.

Para o tratamento térmico, plantas das variedades em estudo enxertadas sobre limoeiro 'Cravo' e cultivadas em vasos de $4,5 \mathrm{dm}^{3}$ foram mantidas em câmara climática a 38 ${ }^{\circ} \mathrm{C}$ por $16 \mathrm{~h}$ de luz e $32{ }^{\circ} \mathrm{C}$ por $8 \mathrm{~h}$ de luz por período de 60 dias. Somente brotações emitidas nestas condições foram então retiradas para microenxertia.

$\mathrm{Na}$ microenxertia, foi utilizada metodologia semelhante à desenvolvida por Murashige et al. (1972) e aperfeiçoada por Navarro et al. (1974). Como microportaenxerto foram empregadas plântulas de citrange 'Troyer' (Poncirus trifoliata Raf. x Citrus paradisi Macf) germinadas no escuro em tubos de ensaio contendo sais de MS (Murashige \& Skoog, 1962). Após o pegamento e desenvolvimento satisfatório do broto, o conjunto foi enxertado por garfagem de topo em limoeiro 'Cravo' com sete meses de idade. Uma mini-câmara úmida com saco plástico foi mantida até a completa adaptação e pegamento (Paiva \& Carvalho, 1993).

Após aclimatação e desenvolvimento adequado, as plantas recuperadas foram novamente indexadas para confirmação da eliminação da sorose utilizando a metodologia descrita anteriormente.

Os resultados dos testes de indexação em laranjeira 'Do Céu' (Tabela 1) indicaram a eficiência da associação dos dois métodos de limpeza na eliminação desta virose, tendo sido obtido $100 \%$ de plantas sadias. Estes resultados são de grande importância, uma vez que o Banco Ativo de Germoplasma de Citros do CCSM-IAC apresenta 16\% de acessos infetados com os vírus do complexo sorose, e a

TABELA 1 - Resultados obtidos nos tratamentos com termoterapia* e microenxertia, para eliminação de vírus do complexo sorose dos citros em acessos de laranja doce (Citrus sinensis). Cordeirópolis, SP, 2000

\begin{tabular}{|c|c|c|c|c|c|c|}
\hline \multirow[b]{2}{*}{ Variedade } & \multirow{2}{*}{$\begin{array}{c}\text { Acesso } \\
\text { BAG }\end{array}$} & \multirow{2}{*}{$\begin{array}{c}\text { Indexação } \\
\text { Sorose** }\end{array}$} & \multicolumn{2}{|c|}{ "Microenxertia } & \multirow[b]{2}{*}{$\begin{array}{c}\text { Re-indexação } \\
\text { Sorose } * *\end{array}$} & \multirow{2}{*}{$\begin{array}{c}\text { Limpeza Sorose } \\
(\%)\end{array}$} \\
\hline & & & $\begin{array}{c}\text { Microenxertos } \\
\text { pegos/feitos }\end{array}$ & $\begin{array}{c}\text { Sucesso } \\
(\%)\end{array}$ & & \\
\hline 'João Nunes' & CV 109 & + & $3 / 16$ & 18,75 & - & 100,00 \\
\hline 'Lima' & CV 09 & + & $3 / 31$ & 9,68 & - & 100,00 \\
\hline 'Pêra Caire' & CV 157 & + & $3 / 34$ & 8,82 & - & 100,00 \\
\hline 'Piralima' & CV 02 & + & $5 / 30$ & 16,67 & - & 100,00 \\
\hline 'Rosa' & CV 95 & + & $5 / 20$ & 25,00 & - & 100,00 \\
\hline 'Rubi' & CV 52 & + & $4 / 30$ & 13,33 & - & 100,00 \\
\hline 'Salustiana' & CN 438 & + & $2 / 26$ & 7,69 & - & 100,00 \\
\hline Média & & & $3,1 / 26,7$ & 14,28 & & $100 \%$ \\
\hline
\end{tabular}




\section{S.A. Carvalho et al.}

aplicação de microenxertia isoladamente tem mostrado eficiência limitada a 63\% dos trabalhos (Carvalho et al., 1998)

$\mathrm{O}$ índice de recuperação de plantas no processo de microenxertia foi em torno de $14 \%$. As perdas no processo estão relacionadas somente à fase in vitro, pois na aclimatação, o processo de garfagem em plantas já estabelecidas em vasos, semelhante ao proposto por Paiva \& Carvalho (1993), tem garantido índices de $100 \%$ de pegamento das plantas.

Além da influência da variedade, os baixos índices observados na recuperação das plantas microenxertadas estão provavelmente associados ao pequeno tamanho do meristema utilizado na operação $(0,4 \mathrm{~mm})$, o que tem garantido a alta eficiência na eliminação do CTV, CEVd e do viróide da cachexia-xiloporose (Carvalho et al., 1998). Os resultados apresentados neste trabalho indicam, portanto que dever ser adotado como rotina o tratamento térmico para os materiais comprovadamente portadores de sorose e daqueles de procedência não determinada, principalmente em trabalhos de introdução de plantas. Isso reforça as afirmações de Roistacher (1985), de que a termoterapia, em associação com a microenxertia, deve ser utilizada, como estratégia para garantir maior segurança nos trabalhos de limpeza clonal

Em relação aos trabalhos de indexação e comprovação da eliminação do vírus, constatou-se grande variabilidade na expressão de sintomas, em função principalmente de variações de temperatura na casa de vegetação. Maior eficiência do processo, facilitando também a avaliação de novas técnicas de eliminação do vírus da sorose, deverão ser obtidos com o aperfeiçoamento de técnicas mais rápidas de detecção, como os baseados em testes moleculares (Garcia et al., 1997, Costa et al., 2001) e em sorologia (Garcia et al., 1994, Djelouah et al., 2000). Como nem todas as expressões do complexo sorose estão associadas ao CPsV (Martin et al., 2001), as dificuldades na implementação destes testes para diagnósticos de rotina estão relacionadas à identificação precisa do componente dos diferentes tipos de sorose, à disponibilidade de antígenos para a produção dos anti-soros e à baixa concentração do vírus nos tecidos.

Plantas dos diferentes clones de laranjeira, livres do vírus da sorose e outros patógenos e pré-imunizados contra estirpes fortes do CTV, estão sendo mantidas em condições protegidas de vetores de vírus e caracterizadas morfologicamente, confirmando a manutenção da fidelidade varietal para utilização nos programa de matrizes e certificação de mudas de citros do Estado de São Paulo.

\section{REFERÊNCIAS BIBLIOGRÁFICAS}

CARVALHO, S.A., MACHADO, M.A. BAPTISTA, C.R. \& MÜLLER, G.W. Shoot-tip graffting and CTV cross protection of the "Centro de Citricultura - IAC" citrus germoplasm collection. Programme \& Abstracts, 14, Conference of the International Organization of Citrus Virologists. Campinas, SP. 1998. p.112.

DERRICK, K.S., BRLANSKY, R.H., GRAÇA, B.J.V., LEE, R.F., TIMMER, L.W. \& NGUYEN, T.K. Partial characterization of a virus associated with citrus ringspot. Phytopathology 78:1298-1301. 1988.

DJELOUAH, K., POTREE, O., BOSCIA, D., D'ONGLHIA, A.M., SAVINO, V. Production of monoclonal antibodies to Citrus psorosis virus. Proceedings, 14, Conference of the International Organization of Citrus Virologists., Riverside, CA. 2000. pp. 152-158.

GARCIA, M.L., DAL BO, E, GRAU, O. \& MILNE, R.G. The closely related citrus ringspot and citrus psorosis viruses have particles of novel filamentous morphology. Journal of Genetic Virology 75:3585-3590. 1994.

GARCIA, M.L., DE LA TORRE, M.E., DAL BO, E., DJELOUAH, K., ROUAG, N., LUISONI, E., MILNE, R.G. \& GRAU, O. Detection of citrus psorosis-ringspot virus using RT-PCR and DAS-ELISA. Plant Pathology 46:830-836. 1997.

MARTIN, S., MiLNE, R.G., ALIOTO, D., GUERRI, J. \& MORENO, P. Psorosis-like symptoms induced by causes other than citrus psorosis virus. Programme \& Abstracts, 15, Conference of the International Organization of Citrus Virologists. Paphus, CY. 2001. p. 83.

MILNE, R.G., DJELOUAH, K., GARCIA, M.L., DAL BO, E. \& GRAU, O. Structure of citrus-ringspot psorosis-associated virus particles: implications for diagnosis and taxonomy. Proceedings, 13, Conference of the International Organization of Citrus Virologists. Riverside, CA. 1996. pp. 189-197.

MÜLLER, G.W. \& COSTA, A.S. Doenças causadas por vírus, viróides e similares em citros. In: Rossetti, V., Müller, G.W. \& Costa, A.S. (Eds). Doenças dos citros causadas por algas, bactérias, fungos e vírus. Campinas, Fundação Cargill, 1993. V.2, pp. 55-84.

MURASHIGE, T \& SKOOG, F. A revised medium for rapid growth and bioassays with tobacco tissue cultures. Physiologia Plantarum 15:473-497. 1962.

MURASHIGE, T., BITTERS, W.P., RANGAN, T.S., NAUER, E.M., ROISTACHER, C.N. \& HOLLIDAY, P.B.O. A technique of shoot apex grafting and its utilization towards recovering virus-free citrus clones. Hort Sicience 7:118-119. 1972.

NAVARRO, L., ROISTACHER, C.N. \& MURASHIGE, T. Improvement of shoot-tip graffting in vitro for virus-free citrus. Journal of the American Society of Horticultural Science 100:471-479. 1974.

PAIVA, L.V. \& CARVALHO, S.A. de. Alternativa para promoção de crescimento in vivo de microenxertos de citros. Pesquisa Agropecuária Brasileira 28:1095-1089. 1993.

ROISTACHER, C.N. A historical review of the major grafttransmissible diseases of citrus. FAO/Regional Office for the Near East, Riverside, 1985. 